\title{
Comparative study of encapsulated and non-encapsulated protocorms for the propagation of Cymbidium aloifolium (L.) Sw. on two different media
}

\author{
Shreeti Pradhan ${ }^{1}$, Tripti Regmi ${ }^{1}$ and Bijaya Pant ${ }^{1 *}$ \\ ${ }^{1}$ Plant Biotechnology and Biochemistry Laboratory, Central Department of Botany, Tribhuvan University, Kirtipur, \\ Kathmandu, Nepal
}

\begin{abstract}
Artificial seed technology is a powerful tool for the propagation of rare and threatened species with high economic value. In the present investigation, medium-sized protocorms of Cymbidium aloifolium were encapsulated with $3 \%$ sodium alginate and $0.2 \mathrm{M}$ calcium chloride dihydrate $\left(\mathrm{CaCl}_{2} .2 \mathrm{H}_{2} \mathrm{O}\right)$ solution. In vitro culture of encapsulated protocorm was carried out on different strength (1.0, 1/2 and $1 / 4)$ of two different liquid media, viz. Murashige and Skoog (MS) and Knudson (Kn C), and full strength (1.0) of both media supplemented with $0.5 \mathrm{mg} / \mathrm{l}$ 6-benzyl aminopurine (BAP) and $0.5 \mathrm{mg} / \mathrm{l}$ á-naphthalene acetic acid (NAA). In vitro germination and seedling development from encapsulated protocorm was compared with non-encapsulated protocorm inoculated on similar culture conditions. Six replicates were used for each treatment. The full strength of MS medium without plant growth regulators was found to be the most favourable condition for germination and plantlet regeneration of $C$. aloifolium. However, earlier seedling development was achieved from encapsulated (after $18.5 \pm 0.84$ weeks of culture) than non-encapsulated (after $20.5 \pm 0.34$ weeks of culture) protocorm. In addition, $100 \%$ of encapsulated protocorms were viable when stored for 20 days at $4^{\circ} \mathrm{C}$, while non-encapsulated protocorms showed only $6.67 \%$ viability on 10 days storage at $4^{\circ} \mathrm{C}$ and later they lost their viability. For acclimatization, plantlets regenerated from encapsulated protocorms were successfully hardened in a potting mixture of cocopeat and clay (3:1) with $85 \%$ survival rate. The present investigation has provided a standard protocol for short- to mid-term storage and efficient conversion of plantlets of $C$. aloifolium through artificial seed technology, which could be beneficial for commercial production of this orchid and its germplasm preservation.
\end{abstract}

Key-words: Protocorms, in vitro, germination, encapsulation, media.

\section{Introduction}

Orchids have tremendous horticultural and medicinal importance. They are prized for their beautiful longlasting flowers exhibiting an incredible range of diversity in size, shape and colour (Corrie and Tandon 1993).

*Correspondence, e-mail: lbijayapant@gmail.com pantbijaya@yahoo.com; Tel: ++977-01-5001714.
Though a single pod of orchids contain many seeds, only less than $5 \%$ germinate in nature as the seeds are minute, non-endospermic with reduced embryo and thus requiring mycorrizal association (Nongdam and Chongtham 2011). Hence, tissue culture technique has been widely used for asymbiotic germination and mass propagation of orchids (Malabadi et al. 2005). Cymbidium aloifolium (L.) Sw. is one of the threatened epiphytic orchids of Nepal. The whole plant of this 
species is used as tonic (Hossain 2011). Paste of leaves and pseudobulbs are used to heal fractured or dislocated bones, and to cure boils and fever (Das et al. 2008; Pant and Raskoti 2013). Besides medicinal value, $C$. aloifolium also fetches a good price in floriculture market because of its attractive long-lasting beautiful flowers. In nature, habitat destruction, indiscriminate collections by orchid lovers and over exploitation for medicinal purposes have led tremendous pressure on the viability of its population. Therefore, efficient conservation strategies are needed to protect this valuable orchid. In this perspective, artificial seed technology, with its advantage of storage and easy handling because of its miniature bead size, could be an alternative method of micropropagation.

Artificial seed or synthetic seed is defined as an artificially encapsulated somatic embryo, protocorm, shoot, node or any other meristematic tissue, which can develop into plant under in vitro and in vivo conditions (Kikowska and Thiem 2011). Artificial seed technology provides a viable approach for in vitro germplasm conservations as it combines the advantages of clonal multiplication with those of seed propagation and storage (Mohanty and Das 2013). However, successful plant recovery from encapsulated vegetative micropropagules mostly depends on the plant species, nutrient composition and period of storage. Initially, only somatic embryos were used as plant material for artificial seed production, but production of uniform somatic embryo at a time is difficult. As a result, efforts have been made for encapsulation in linear copolymer such as alginic acid (an anionic polysaccharide) of in vitroderived non-embryogenic plant material (protocorm, shoot tip, bud, etc.) since last few years (Standardi and Piccioni 1998). Plant tissues encapsulated within the alginate matrix are protected from physical and environmental injury. The matrix also reduces dehydration and grips the explants inside the gel during storage (Ara et al. 2000; Mohanty and Das 2013). Protocorm and protocorm-like bodies are found to be the most efficient explants for artificial seed development due to their superior regenerative character (Saiprasad and Polisetty 2003).
In this study an attempt has been made to produce the artificial seed by encapsulating the protocorms of C. aloifolium. The present investigation was undertaken to study the best medium for in vitro germination and plantlet conversion of $3 \%$ alginate encapsulated and non-encapsulated protocorms of C. aloifolium. The results of present investigation might be useful for clonal propagation and short- to mid-term storage of this species for germplasm preservation.

\section{Materials and Method}

\section{PLANT MATERIAL}

Protocorms developed from in vitro culture of seeds of C. aloifolium were used as explants for present investigation. For propagation and production through protocorms, the immature undehisced capsules of $C$. aloifolium were collected from wild. The capsules were washed under running tap water for 30 minutes and surface sterilized with $70 \%$ alcohol (2 minutes) and 1\% sodium hypochlorite solution (15 minutes). Finally, it was rinsed in sterile water for at least three times and kept ready for cut after drying in filter paper. The capsule was cut longitudinally with sterile surgical blade and exposed the yellowish white seeds. Seeds were inoculated on MS medium and kept in culture room maintained with temperature $25 \pm 2{ }^{\circ} \mathrm{C}$ under $16 / 8 \mathrm{~h}$ photoperiod from cool-white fluorescent light. The seeds were found swollen and became spherule in shape after 8-10 weeks of culture. These spherule structures soon turned green in colour and developed protocorms after 12 weeks of culture. Tissues after 20-25 days of protocorm initiation were used for producing artificial seeds (encapsulated protocorm).

\section{CULTURE MEDIUM}

Here, MS (Murashige and Skoog 1962) and Kn C (Knudson 1922) media were used as the basal medium for in vitro germination and seedling development of encapsulated and non-encapsulated protocorms. Full (1.0), half (1/2) and quarter (1/4) strengths of both MS and $\mathrm{Kn} \mathrm{C}$ liquid media supplemented with or without 
plant growth regulators, viz. BAP $(0.5 \mathrm{mg} / \mathrm{l})$ and NAA $(0.5 \mathrm{mg} / \mathrm{l})$ were used for this investigation (Table 1$)$. The medium was fortified with $30 \mathrm{~g} / \mathrm{l}$ sucrose as carbon source and with or without different plant growth regulators (BAP and NAA). The $\mathrm{pH}$ of the media was adjusted to 5.8 with $0.1 \mathrm{~N} \mathrm{NaOH}$ or $\mathrm{HCl}$. About $20 \mathrm{ml}$ of media was dispensed into each culture tube $(150 \times 25 \mathrm{~mm}$, Borosil $)$ and autoclaved at $121^{\circ} \mathrm{C}$ for $20 \mathrm{~min}$ at $1.05 \mathrm{~kg} / \mathrm{cm}^{2}$ pressure. All cultures were maintained at $25 \pm 2{ }^{\circ} \mathrm{C}$ for 16/8 h (light/dark) photoperiod using cool white fluorescent light.

\section{ENCAPSULATION AND INOCULATION}

Medium-sized protocorms (with $3 \pm 1 \mathrm{~mm}$ diameter) were separated individually with the help of sterile forceps and were mixed in the encapsulation matrix consisting of $3 \%(\mathrm{w} / \mathrm{v})$ sodium alginate solution. Alginate solution containing single protocorm was taken with micropipette and gently dropped in calcium chloride dihydrate $\left(\mathrm{CaCl}_{2} \cdot 2 \mathrm{H}_{2} \mathrm{O}\right)$ solution $(0.2 \mathrm{M})$. The droplets containing single protocorm were left in $\mathrm{CaCl}_{2} \cdot 2 \mathrm{H}_{2} \mathrm{O}$ solution for at least 30 minutes to achieve polymerization of sodium alginate. After polymerization, each alginate bead contained a single protocorm (Figure 1a). The beads, called as encapsulated protocorms or synthetic seeds or artificial seeds, were washed with sterile water to avoid sticking together and then surface dried in sterilized filter paper. Encapsulated and non-encapsulated protocorms were inoculated on different strengths of MS and Kn C liquid media supplemented with or without hormones to determine the most appropriate conditions for their germination and development (Table 1 \& 2). The whole experiment was performed under laminar flow cabinet to prevent from any form of contaminations. The cultures were then kept at $25 \pm 2{ }^{\circ} \mathrm{C}$ under $16 / 8 \mathrm{~h}$ photoperiod in culture room. A set of 100 artificial seeds were kept in sterile Petridish sealed with parafilm and stored at $4^{\circ} \mathrm{C}$ as well as at room temperature $\left(21 \pm 2^{\circ} \mathrm{C}\right)$ for 30 days. They were taken out at regular intervals of 10 days and inoculated on optimized medium, i.e. hormone free full strength of liquid MS medium, to observe their germination and survival percentage. The survival rate (i.e., the viability of protocorms) was determined by percentage of germination and plantlet development on the medium.

\section{ACCLIMATIZATION}

In vitro plants with well-developed shoots and roots obtained from encapsulated protocorms of C. aloifolium were ready for acclimatization. Well rooted plantlets were taken out from culture room and rinsed with sterile lukewarm water to remove media sticking to them. They were treated with $0.05 \%$ fungicide (Bavistin) solution for 5 minutes, again rinsed with sterile water and blotted dry in filter paper. The plantlets were then transferred to clay and plastic pots containing cocopeat and clay in the ratio of $3: 1$ as potting mixture. The transplanted plants were finally kept in greenhouse for further acclimatization and were observed regularly. Appropriate care was taken during watering and fertilizing with the mixture of nitrogen, phosphorous and potassium (NPK) in the ratio of 20:10:10.

\section{STATISTICAL ANALYSIS}

The data are presented as mean \pm SD for each treatment. There were 6 replicates per treatment and each experiment was repeated twice. The differences in mean germination percentage between the medium and among the medium supplemented with different growth hormones were analysed using one-way analysis of variance (ANOVA) in SPSS version 16.0 (SPSS Inc. USA).

\section{Results}

Encapsulated and non-encapsulated protocorms were successfully inoculated singly on different strengths (1, 1/2, and $1 / 4$ ) of liquid MS and Kn C media and full strength of both media fortified with $0.5 \mathrm{mg} / \mathrm{l} \mathrm{BAP}$ and NAA for their germination and seedling development. It was found that in vitro germination of encapsulated protocorms was started within 4.33 to 5.00 weeks of culture on all the culture conditions of MS medium and 6.17 to 7.67 weeks of culture on Kn C medium (Table 1), whereas germination of non-encapsulated protocorms 
Table 1. Effect of MS and Kn C liquid media on in vitro germination and seedling development from encapsulated protocorm of Cymbidium aloifolium.

\begin{tabular}{|c|c|c|c|c|c|c|c|}
\hline \multirow[t]{2}{*}{ Media } & \multirow[t]{2}{*}{ Plant hormones } & \multicolumn{4}{|c|}{ Observation in weeks (Mean \pm SE) } & \multirow{2}{*}{$\begin{array}{l}\text { Seedling } \\
\text { development } \\
\text { (weeks of } \\
\text { culture) }\end{array}$} & \multirow{2}{*}{$\begin{array}{l}\% \text { of seedling } \\
\text { development }\end{array}$} \\
\hline & & $\begin{array}{l}\text { Initiation of } \\
\text { germination }\end{array}$ & $\begin{array}{l}\text { Initiation of } \\
\text { shoot } \\
\text { primordia }\end{array}$ & $\begin{array}{l}\text { Initiation of } \\
\text { leaf } \\
\text { primordia }\end{array}$ & $\begin{array}{l}\text { Initation of } \\
\text { root } \\
\text { primordia }\end{array}$ & & \\
\hline MS & & $4.33 \pm 0.21$ & $5.67 \pm 0.42$ & $8.00 \pm 0.26$ & $13.00 \pm 0.93$ & $18.50 \pm 0.84$ & 100.00 \\
\hline $1 / 2 \mathrm{MS}$ & & $4.67 \pm 0.33$ & $6.67 \pm 0.61$ & $9.00 \pm 0.36$ & $15.00 \pm 0.68$ & $20.50 \pm 0.70$ & 66.67 \\
\hline $1 / 4 \mathrm{MS}$ & & $5.00 \pm 0.52$ & $7.00 \pm 0.68$ & $9.50 \pm 0.72$ & $13.33 \pm 0.42$ & $21.83 \pm 0.54$ & 66.67 \\
\hline \multirow[t]{3}{*}{ MS } & $0.5 \mathrm{BAP}+0.5 \mathrm{NAA}$ & $5.00 \pm 0.45$ & $6.67 \pm 0.61$ & $10.83 \pm 0.79$ & $14.50 \pm 0.22$ & $22.50 \pm 0.22$ & 33.33 \\
\hline & $F$-value & 0.655 & 0.952 & 4.132 & 2.295 & 7.568 & \\
\hline & $p$-value & 0.589 & 0.434 & 0.020 & 0.109 & 0.001 & \\
\hline Kn C & & $6.17 \pm 0.40$ & $7.00 \pm 0.45$ & $8.67 \pm 0.84$ & $12.83 \pm 0.87$ & $19.33 \pm 0.95$ & 66.67 \\
\hline $1 / 2 \mathrm{KnC}$ & & $6.50 \pm 0.42$ & $8.00 \pm 0.57$ & $10.50 \pm 0.61$ & $17.00 \pm 1.31$ & $22.00 \pm 0.73$ & 50.00 \\
\hline $1 / 4 \mathrm{KnC}$ & & $7.67 \pm 0.49$ & $8.83 \pm 0.40$ & $12.17 \pm 0.47$ & $17.50 \pm 0.56$ & $22.83 \pm 0.30$ & 66.67 \\
\hline \multirow[t]{3}{*}{ Kn C } & $0.5 \mathrm{BAP}+0.5 \mathrm{NAA}$ & $7.00 \pm 0.36$ & $10.33 \pm 0.49$ & $15.67 \pm 0.80$ & $21.50 \pm 0.34$ & $24.00 \pm 0.00$ & 33.33 \\
\hline & $F$-value & 2.359 & 8.471 & 18.023 & 17.163 & 10.223 & \\
\hline & $p$-value & 0.102 & 0.001 & $<0.001$ & $<0.001$ & $<0.001$ & \\
\hline
\end{tabular}

Culture conditions: various strength of MS and Kn C liquid media, $25 \pm 2^{\circ} \mathrm{C}, 24$ weeks, $16 / 8$ hrs photoperiod; 6 replicates were used in each condition. $p$-value based on one-way ANOVA ( $\mathrm{df} 3,23)$.

Table 2. Effect of MS and Kn C liquid media on in vitro germination and seedling development from non-encapsulated protocorm of Cymbidium aloifolium.

\begin{tabular}{|c|c|c|c|c|c|c|c|}
\hline \multirow[t]{2}{*}{ Media } & \multirow[t]{2}{*}{ Plant hormones } & \multicolumn{4}{|c|}{ Observation taken in weeks (Mean \pm SE) } & \multirow{2}{*}{$\begin{array}{l}\text { Seedling } \\
\text { development } \\
\text { (weeks of } \\
\text { culture) }\end{array}$} & \multirow{2}{*}{$\begin{array}{l}\% \text { of seedling } \\
\text { development }\end{array}$} \\
\hline & & $\begin{array}{l}\text { Initiation of } \\
\text { germination }\end{array}$ & $\begin{array}{l}\text { Initiation of } \\
\text { shoot } \\
\text { primordia }\end{array}$ & $\begin{array}{l}\text { Initiation of } \\
\text { leaf primordia }\end{array}$ & $\begin{array}{l}\text { Initation of } \\
\text { root } \\
\text { primordia }\end{array}$ & & \\
\hline MS & & $4.17 \pm 0.17$ & $6.00 \pm 0.36$ & $10.00 \pm 0.68$ & $13.83 \pm 0.65$ & $20.50 \pm 0.34$ & 83.33 \\
\hline $1 / 2 \mathrm{MS}$ & & $4.83 \pm 0.65$ & $6.67 \pm 0.71$ & $10.50 \pm 0.84$ & $14.33 \pm 1.12$ & $20.80 \pm 0.30$ & 66.67 \\
\hline $1 / 4 \mathrm{MS}$ & & $4.67 \pm 0.33$ & $6.67 \pm 0.42$ & $11.00 \pm 1.67$ & $15.00 \pm 0.63$ & $21.33 \pm 0.21$ & 66.67 \\
\hline \multirow[t]{3}{*}{ MS } & $0.5 \mathrm{BAP}+0.5 \mathrm{NAA}$ & $5.33 \pm 0.42$ & $8.00 \pm 0.68$ & $15.00 \pm 0.57$ & $23.50 \pm 0.22$ & $23.83 \pm 0.16$ & 16.67 \\
\hline & $F$-value & 1.244 & 2.184 & 4.846 & 39.546 & 32.255 & \\
\hline & $p$-value & 0.320 & 0.122 & 0.011 & $<0.001$ & $<0.001$ & \\
\hline Kn C & & $5.17 \pm 0.30$ & $6.67 \pm 0.33$ & $10.50 \pm 1.56$ & $14.50 \pm 1.08$ & $21.17 \pm 0.79$ & 66.67 \\
\hline $1 / 2 \mathrm{KnC}$ & & $6.00 \pm 0.36$ & $8.17 \pm 0.65$ & $12.83 \pm 1.85$ & $15.33 \pm 0.88$ & $21.67 \pm 0.55$ & 50.00 \\
\hline $1 / 4 \mathrm{Kn} \mathrm{C}$ & & $6.33 \pm 0.50$ & $7.50 \pm 0.43$ & $14.33 \pm 2.29$ & 0 & 0 & 0 \\
\hline \multirow[t]{3}{*}{ Kn } & $0.5 \mathrm{BAP}+0.5 \mathrm{NAA}$ & $6.50 \pm 0.76$ & $9.17 \pm 0.47$ & $17.50 \pm 1.84$ & 0 & 0 & 0 \\
\hline & $F$-value & 1.333 & 4.708 & 2.371 & 151.516 & 651.548 & \\
\hline & $p$-value & 0.292 & 0.012 & 0.101 & $<0.001$ & $<0.001$ & \\
\hline
\end{tabular}

Culture conditions: various strength of MS and Kn C liquid media, $25 \pm 2^{\circ} \mathrm{C}$, 24 weeks, 16/8 hrs photoperiod; 6 replicates were used in each condition. $p$-value based on one-way ANOVA (df 3, 23). 
started on the range between 4.17 to 5.33 and 5.17 to 6.50 weeks of culture on all the culture conditions of MS and Kn C medium respectively. Germinated encapsulated and non-encapsulated protocorms further underwent successive phases of plantlet development within 18-24 weeks of culture.

Hormone-free, full strength of MS medium was the most appropriate condition for the initiation of first shoot, leaf and root primordia from encapsulated protocorms (Table 1), the initiation of which took $5.67 \pm$ $0.42,8.00 \pm 0.26$ and $13.00 \pm 0.93$ weeks of culture respectively as compared to other tested conditions of MS medium. In hormone-free, full strength of MS medium, the complete seedling was observed on shortest period of time (18.50 \pm 0.84 weeks of culture) with $100 \%$ seedling development compared to other tested conditions of MS medium (Table 1). One-way ANOVA showed that among the growth parameters studied only the initiation of leaf primordia and seedling development varied significantly among different conditions of MS medium ( $p<0.05$; Table 1$)$. Hormonefree, full strength of $\mathrm{Kn} \mathrm{C}$ medium exhibited earlier shoot, leaf and root development than did by other tested conditions of Kn C medium ( $p \leq 0.001$; Table 1$)$. In this medium, the whole seedling was also developed on shortest period of time (19.33 \pm 0.95 weeks of culture; $p$ $<0.001$ ) with highest percentage $(66.67 \%)$ of seedling development compared to other culture conditions (Table 1).

Hormone-free full strength of MS medium was also found to be the effective condition for initial development of shoot $(6.00 \pm 0.36$ weeks of culture),
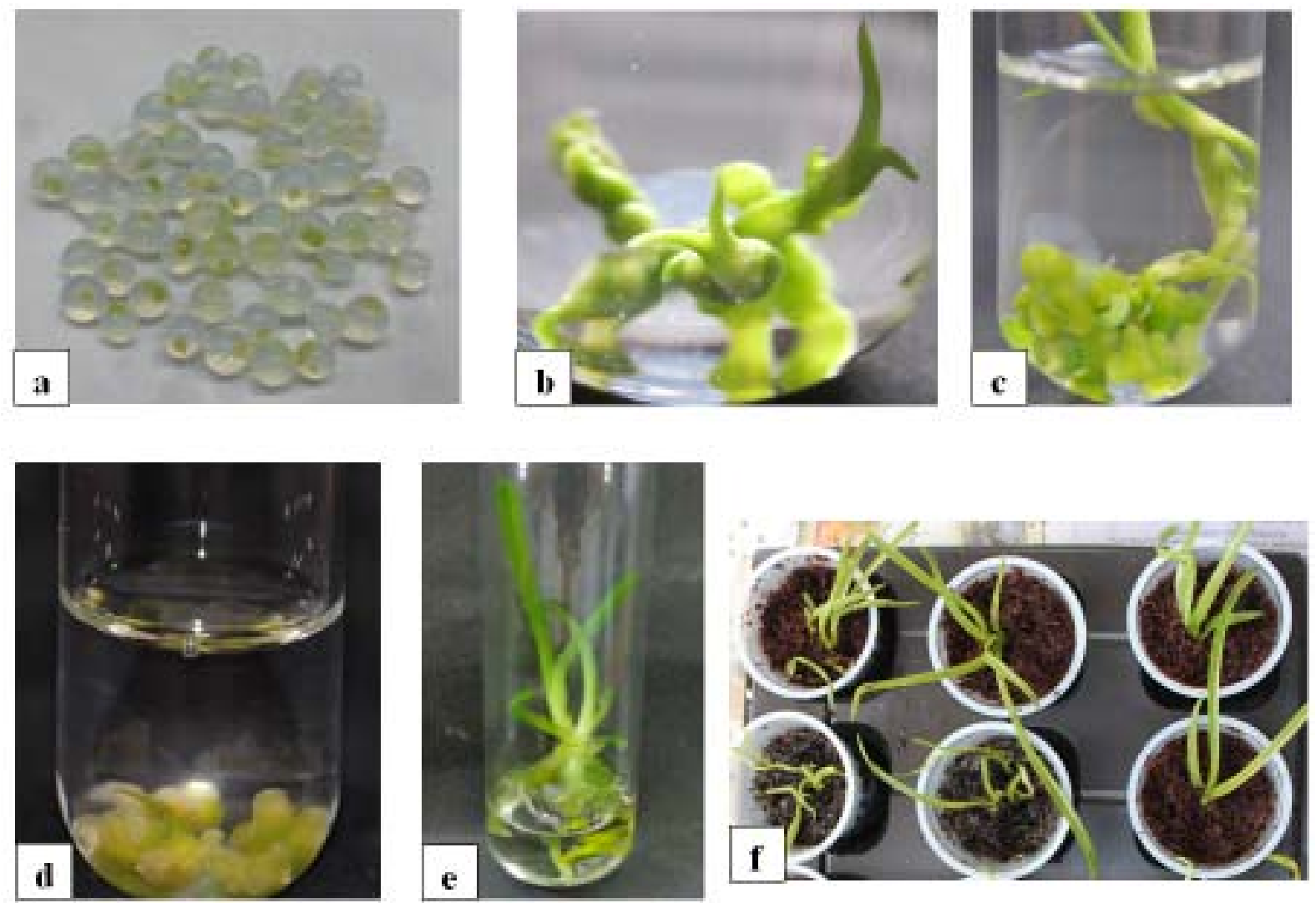

Figure 1. Regeneration of plantlets from encapsulated and non-encapsulated protocorm of Cymbidium aloifolium: (a) protocorms encapsulated with $3 \%$ sodium alginate and $0.2 \mathrm{M}$ calcium chloride solution; (b \& c) encapsulated protocorm gave rise to shoot buds and plant on hormone free MS medium; (d) development of shoot buds from non-encapsulated protocorm on $1 / 2$ MS medium; (e) encapsulated protocorm gave rise to complete seedling on hormone free MS medium; (f) hardening of in vitro plantlets on potting mixture of cocopeat and clay (ratio: 3:1). 
leaf $(10.00 \pm 0.68$ weeks of culture $)$ and root $(13.83 \pm 0.65$ weeks of culture) primordia from in vitro germination of single non-encapsulated protocorm (Table 2). One-way ANOVA showed that value of all the growth parameters except initiation of germination and shoot primordia varied significantly among different conditions of MS medium ( $p<0.01$; Table 2 ). In this culture condition, the complete seedling was observed on shortest period of time (20.50 \pm 0.34 weeks of culture; $p<0.001)$ with highest percentage (83.33\%) of seedling development compared to other tested conditions of MS medium (Table 2). Nonencapsulated protocorms also showed earlier development of shoot $(6.67 \pm 0.33$ weeks of culture), leaf (10.50 \pm 1.56 weeks of culture) and root (14.50 \pm 1.08 weeks of culture) on full strength of $\mathrm{Kn} \mathrm{C}$ medium as compared to different culture conditions of $\mathrm{Kn} \mathrm{C}$ medium. However, the result was significant only in the case of shoot and root initiation (Table 2). On full strength of Kn C medium, complete seedling was observed on shortest period of time (after $21.17 \pm 0.79$ weeks of culture; $p<0.001$ ) with highest percentage (66.67\%) of seedling development compared to other culture conditions (Table 2).

Encapsulated protocorms stored at $4^{\circ} \mathrm{C}$ were greenish and healthy, whereas those stored at room temperature (RT) became pale and reduced its size. They showed $100 \%$ viability when stored for 20 days at $4^{\circ} \mathrm{C}$ while their viability percentage decreased to $66.67 \%$ on 60 days of storage. Encapsulated protocorms stored at RT showed only $76.67 \%$ viability up to 10 days of storage, viability decreased to $10 \%$ on 40 days and no viability was observed after 50 days of storage due to desiccation. However, only $6.67 \%$ of non-encapsulated protocorms stored for 10 days at $4{ }^{\circ} \mathrm{C}$ were viable and no viability was observed after 20 days of storage. Nonencapsulated protocorms also failed to give response when stored at RT (Table 3).

In vitro seedling with well-developed roots obtained from encapsulated prototocorm after attaining the height of 4-5 cm was acclimatized in plastic or clay pot containing cocopeat and clay in the ratio of 3:1 (Figure 1f). Almost $85 \%$ seedlings of $C$. aloifolium were successfully survived under this potting mixture.

\section{Discussion}

Standard protocol for the production and propagation of synthetic seed of orchid is very limited. Hence, a comparative study of in vitro culture between encapsulated and non-encapsulated protocorms of $C$. aloifolium was carried out. The artificial seed technology, based on vegetative propagules, like protocorm, shoot tip, bud, nodal explants, etc., may be useful for large-scale propagation, short- to long-term conservation and germplasm exchange of desirable species (Kikowska and Thiem 2011). Encapsulation of protocorms offers efficient techniques for clonal propagation of elite genotypes. In the present investigation, the encapsulated and non-encapsulated protocorms of $C$. aloifolium showed varied responses on their germination and seedling development on all the conditions of MS and Kn C medium. Encapsulated protocorms took longer time for germination than did by non-encapsulated protocorms. It may be due to the delay on rupturing of the alginate matrix to emerge the tissue outside and came in contact with nutrient medium. However, encapsulated protocorms gave earlier response on their conversion into complete seedling than non-encapsulated protocorms.

Though all the tested media successfully supported the conversion of encapsulated and non-encapsulated protocorms into whole plantlet, the duration for development of shoot, leaf and root showed varied responses. It may be due to the nature of two different media and different concentration of plant growth hormones. Both encapsulated and non-encapsulated protocorms first gave rise to protocorm-like bodies and shoot buds, which later underwent differentiation into leaf, root and finally developed complete seedling (Figure b \& c). Encapsulated protocorms gave their earlier germination response and converted into seedlings on hormone-free full strength of MS medium rather than on other tested conditions of MS and Kn C media. On different conditions of $\mathrm{Kn} \mathrm{C}$ medium, encapsulated protocorms germinated and multiplied slowly and developed $33.33 \%$ to $66.67 \%$ of seedlings (Table 1). A similar result was found on non-encapsulated protocorms as well. However, $1 / 4 \mathrm{Kn} \mathrm{C}$ and $\mathrm{Kn} \mathrm{C}+0.5$ 
Table 3. Effect of storage temperature and duration of storage on regeneration of plantlet of Cymbidium aloifolium.

\begin{tabular}{|c|c|c|c|c|c|c|}
\hline Explant & Media & $\begin{array}{l}\text { Storage } \\
\text { temperature }\end{array}$ & $\begin{array}{l}\text { Duration of } \\
\text { storage (days) }\end{array}$ & $\begin{array}{l}\text { Total no. of } \\
\text { tested explant }\end{array}$ & $\begin{array}{l}\text { No. of ruptured } \\
\text { explant }\end{array}$ & $\begin{array}{l}\text { Conversion of } \\
\text { explant into } \\
\text { plantlets (\%) }\end{array}$ \\
\hline \multirow{12}{*}{$\begin{array}{l}\text { Encapsulated } \\
\text { protocorms }\end{array}$} & \multirow[t]{12}{*}{ MS } & \multirow[t]{6}{*}{$4^{\circ} \mathrm{C}$} & 10 & 30 & 30 & 100 \\
\hline & & & 20 & 30 & 30 & 100 \\
\hline & & & 30 & 30 & 28 & 93.33 \\
\hline & & & 40 & 30 & 24 & 80.00 \\
\hline & & & 50 & 30 & 22 & 73.33 \\
\hline & & & 60 & 30 & 20 & 66.67 \\
\hline & & \multirow[t]{6}{*}{$\mathrm{RT}$} & 10 & 30 & 23 & 76.67 \\
\hline & & & 20 & 30 & 17 & 56.67 \\
\hline & & & 30 & 30 & 12 & 40 \\
\hline & & & 40 & 30 & 3 & 10 \\
\hline & & & 50 & 30 & 0 & 0 \\
\hline & & & 60 & 30 & 0 & 0 \\
\hline \multirow{12}{*}{$\begin{array}{l}\text { Non-encapsulated } \\
\text { protocorms }\end{array}$} & \multirow[t]{12}{*}{ MS } & \multirow[t]{6}{*}{$4^{\circ} \mathrm{C}$} & 10 & 30 & 2 & 6.67 \\
\hline & & & 20 & 30 & 0 & 0 \\
\hline & & & 30 & 30 & 0 & 0 \\
\hline & & & 40 & 30 & 0 & 0 \\
\hline & & & 50 & 30 & 0 & 0 \\
\hline & & & 60 & 30 & 0 & 0 \\
\hline & & \multirow[t]{6}{*}{ RT } & 10 & 30 & 0 & 0 \\
\hline & & & 20 & 30 & 0 & 0 \\
\hline & & & 30 & 30 & 0 & 0 \\
\hline & & & 40 & 30 & 0 & 0 \\
\hline & & & 50 & 30 & 0 & 0 \\
\hline & & & 60 & 30 & 0 & 0 \\
\hline
\end{tabular}

Culture conditions: MS liquid media, RT- room temperature $\left(21 \pm 2^{\circ} \mathrm{C}\right)$.

BAP + 0.5 NAA were not suitable for the recovery of non-encapsulated protocorms into whole plantlets (Table 2). It may be due to the low amount of macro- and micro-nutrients present in Kn C medium which affected the growth of explants of $C$. Aloifolium. The present findings was supported by Hossain et al. (2009), who found only $50 \%$ seed germination of $C$. aloifolium on Kn C medium.

In the present investigation, non-encapsulated protocorms germinated earlier on hormone-free MS medium, but later their growth decreased and took longer time for conversion into whole plantlet $(20.5 \pm 0.34$ weeks of culture) than encapsulated protocorms $(18.5 \pm 0.84$ weeks of culture). It was found that $100 \%$ of encapsulated protocorms underwent differentiation to develop complete seedlings (Figure 1e), while nonencapsulated protocorms showed $83.33 \%$ of seedling development on hormone-free MS medium. Similar results were also reported by various researchers. Corrie and Tandon (1993) reported 100\% conversion of encapsulated protocorm-like bodies (PIBs) into plantlet under in vitro condition in Cymbidium giganteum. Similarly, Sarmah et al. (2010) found 94.9\% conversion frequency of encapsulated PLBs of Vanda coerulea. Nagananda et al. (2011) achieved 95\% conversion of encapsulated PLBs of Flickingeria nodosa into plantlets after 3 months of storage at $4^{\circ} \mathrm{C}$. Gantait et al. (2012) obtained $96.4 \%$ conversion of $3 \%$ alginate coated PLBs of Aranda $\times$ Vanda. to aThe present findings were dissimilar to the reports of Mohanty and Das (2013) 
who found that MS medium supplemented with $2 \mathrm{mg} / \mathrm{l}$ BAP was efficient for $100 \%$ conversion of encapsulated PLB's into plantlets on Dendrobium densiflorum. Similarly, Qin et al. (2008) found that modified MS with $4 \%$ maltose and BA (1 mg/l) and NAA (1 mg/l) favoured germination and seedling growth of Dendrobium huoshanense by using $4 \%$ sodium alginate. Datta et al. (1999) reported 88\% of conversion of artificial seeds into plantlets in Geodorum densiflorum on modified Knudson medium supplemented with BAP (1 mg/l) and NAA (1 mg/l).

In both temperatures ( $4^{\circ} \mathrm{C}$ and $\left.\mathrm{RT}\right)$, the germination percentage of encapsulated protocorms gradually declined with increased in storage time. The present finding is consistent with the results obtained by Singh (1991) in Spathoglottis plicata; Malemnganba et al. (1996) in Phaius tankervilleae; Datta et al. (1999) in Geodorum densiflorum; Saiprasad and Polisetty (2003) in the species of Dendrobium, Oncidium and Cattleya; and Pradhan et al. (2014) in Cymbidium aloifolium. Nonencapsulated protocorms stored for 10 days showed only $6.67 \%$ of regeneration of plantlet at $4^{\circ} \mathrm{C}$. Later, nonencapsulated protocorms stored at $4^{\circ} \mathrm{C}$ and RT became achlorophyllous, shrinked and lost their viability completely. Hence from the observation, it is concluded that encapsulated protocorms have higher regeneration capacity than non-encapsulated protocorms (Table 3). The coating of alginate on encapsulated protocorms not only protects them from desiccation but also enhances their growth on nutrient media. Thus, encapsulated protocorms can be stored for short- to mid-term for germplasm preservation and can be easily delivered from laboratory to nursery.

The present study shows that the hormone-free full strength of liquid MS medium is the most effective condition for germination and regeneration of plantlets from encapsulated and non-encapsulated protocorms of C. aloifolium. High regeneration potentiality and strong viability of encapsulated compared to nonencapsulated protocorms support that the encapsulation technique is a promising tool for storage and supply of demanded plant material for propagation and exchange of germplasm. It is therefore concluded that protocorms encapsulated with $3 \%$ alginate can be used as alternative planting materials for germplasm preservation, short- to mid-term storage, and mass propagation of C. aloifolium.

\section{Acknowledgements}

Authors are grateful to Central Department of Botany, Tribhuvan University, Kathmandu, Nepal for providing all laboratory facilities for this investigation. We are also thankful to Nepal Academy of Science and Technology (NAST), Khumaltar, Lalitpur, Nepal for providing the financial assistance to carry out the present research work.

\section{References}

Ara H., Jaiswal U., and Jaiswal V.S. 2000. Synthetic seed: prospects and limitations. Current Science, 78: 1438-1444.

Corrie S. and Tandon P. 1993. Propagation of Cymbidium giganteum Wall. through high frequency conversion of encapsulated protocorms under in vivo and in vitro conditions. Indian Journal of Experimental Biology, 31: 61-64.

Das P.K., Sahoo S. and Bal S. 2008. Ethnobotanical studies on orchids of Niyamgiri Hill Ranges, Orissa, India. Ethnobotanical Leaflets, 12: 70-78.

Datta K.B., Kanjilal B. and De Sarker D. 1999. Artificial seed technology: Development of a protocol in Geodorum densiflorum (Lam) Schltr., an endangered orchid. Current Science, 76(8): 1142-1145.

Gantait S., Bustam S. and Sinniah U.R. 2012. Alginateencapsulation, short-term storage and plant regeneration from protocorm-like bodies of Aranda Wan Chark Kuan 'Blue'× Vanda coerulea Grifft. ex. Lindl. (Orchidaceae). Plant Growth Regulation, 68(2): 303-311.

Hossain M.M. 2011. Therapeutic orchids: traditional uses and recent advances - An overview. Fitoterapia, 82(2): 102-140.

Hossain M.M., Sharma M. and Pathak P. 2009. Cost effective protocol for in vitro mass propagation of Cymbidium aloifolium (L.) Sw. - a medicinally important orchid. Engineering in Life Sciences, 9(6): 444-453.

Kikowska M. and Thiem B. 2011. Alginate-encapsulated shoot tips and nodal segments in micropropagation of medicinal plants. A review. Herba Polonica, 57(4): 45-57.

Knudson L. 1922. Non-symbiotic germination of orchid seeds. Botanical Gazette, 73: 1-25.

Malabadi R.B., Mulgund G.S. and Kallappa N. 2005. Micropropagation of Dendrobium nobile from shoot tip sections. Journal of Plant Physiology, 162(4): 473-478.

Malemnganba H., Ray B.K., Bhattacharyya S. and Deka P.C. 1996. Regeneration of encapsulated protocorms of Phaius tankervilliae stored at low temperature. Indian Journal of Experimental Biology, 34(8): 802-805. 
Mohanty P. and Das J. 2013. Synthetic seed technology for short-term conservation of medicinal orchid Dendrobium densiflorum Lindl. ex Wall and assessment of genetic fidelity of regenerants. Plant Growth Regulation, 70(3): 297-303.

Murashige T. and Skoog F. 1962. A revised medium for rapid growth and bio assays with tobacco tissue cultures. Physiologia Plantarum, 15(3): 473-497.

Nagananda G.S., Satishchandra N. and Rajath S. 2011. Regeneration of encapsulated protocorm-like bodies of medicinally important vulnerable orchid Flickingeria nodosa (Dalz.) Seidenf. International Journal of Botany, 7(4): 310313.

Nongdam P. and Chongtham N. 2011. In vitro rapid propagation of Cymbidium aloifolium (L.) Sw.: a medicinally important orchid via seed culture. Journal of Biological Sciences, 11(3): 254-260.

Pant B. and Raskoti B.B. 2013. Medicinal Orchids of Nepal. Himalayan Map House Pvt. Ltd., Kathmandu, Nepal.

Pradhan S., Tiruwa B., Subedee B.R. and Pant B. 2014. In vitro germination and propagation of a threatened medicinal orchid, Cymbidium aloifolium (L.) Sw. through artificial seed. Asian Pacific Journal of Tropical Biomedicine, 4(12): 971-976.

Qin Z., Zhao T., Qiu J., Lin Y. and Cai Y. 2008. Germination and propagartors of artificial seeds of Dendrobium huoshanense. Chinese Journal of biotechnology, 24(5): 803809.

Saiprasad G.V.S. and Polisetty R. 2003. Propagation of three orchid genera using encapsulated protocorm-like bodies. In Vitro Cellular and Developmental Biology-Plant, 39(1): 4248.

Sarmah D.K., Borthakur M. and Borua P.K. 2010. Artificial seed production from encapsulated PLBs regenerated from leaf base of Vanda coerulea Grifft. ex. Lindl. - an endangered orchid. Current Science, 98(5): 686-690.

Singh F. 1991. Encapsulation of Spathoglottis plicata protocorms. Lindleyana, 6(2): 61-63.

Standardi A. and Piccioni E. 1998. Recent perspectives on synthetic seed technology using nonembryogenic in vitroderived explants. International Journal of Plant Sciences, 159(6): 968-978. 